\title{
Laboratory diagnosis of amebiasis in a sample of students from southeastern Brazil and a comparison of microscopy with enzyme-linked immunosorbent assay for screening of infections with Entamoeba sp.
}

\author{
Valeriana Valadares Pereira ${ }^{[1]}$, Abiqueila da Silva Conceição ${ }^{[1]}$, \\ Leandro Henrique Silva Maximiano ${ }^{[1]}$, Leonardo de Queiroz Gomes Belligoli ${ }^{[1]}$ \\ and Eduardo Sergio da Silva ${ }^{[1]}$
}

[1]. Campus Centro-Oeste Dona Lindu, Universidade Federal de São João del-Rei, Divinópolis, MG.

\begin{abstract}
Introduction: Epidemiological studies on amebiasis have been reassessed since Entamoeba histolytica and E. dispar were first recognized as distinct species. Because the morphological similarity of these species renders microscopic diagnosis unreliable, additional tools are required to discriminate between Entamoeba species. The objectives of our study were to compare microscopy with ELISA kit (IVD®) results, to diagnose $E$. histolytica infection, and to determine the prevalence of amebiasis in a sample of students from southeastern Brazil. Methods: In this study, diagnosis was based on microscopy due to its capacity for revealing potential cysts/trophozoites and on two commercial kits for antigen detection in stool samples. Results: For 1,403 samples collected from students aged 6 to 14 years who were living in Divinópolis, Minas Gerais, Brazil, microscopy underestimated the number of individuals infected with E. histolytica/E. dispar (5.7\% prevalence) compared with the ELISA kit (IVD $\left.{ }^{\circledR}\right)$-based diagnoses (15.7\% for E. histolytica/E. dispar). A comparison of the ELISA (IVD®) and light microscopy results returned a $20 \%$ sensitivity, 97\% specificity, low positive predictive value, and high negative predictive value for microscopy. An ELISA kit (TechLab ${ }^{2}$ ) that was specific for E. histolytica detected a 3.1\% (43/1403) prevalence for E. histolytica infection. Conclusions:

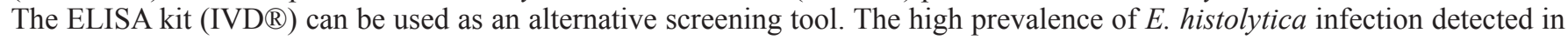
this study warrants the implementation of actions directed toward health promotion and preventive measures.
\end{abstract}

Keywords: Entamoeba histolytica. Entamoeba dispar. Microscopy. ELISA.

\section{INTRODUCTION}

Amebiasis is a human infection caused by Entamoeba histolytica, a protozoan of cosmopolitan distribution, with or without clinical manifestations ${ }^{1}$. Infection by the species Entamoeba dispar is approximately 10 times more common than infection by $E$. histolytica ${ }^{2}$. Given the morphological similarity of these species, diagnosis based on light microscopy can yield either under- or overestimation of infection rates, leading to unnecessary treatment ${ }^{3}$. The sensitivity of microscopy ranges from $5 \%$ to $60 \%$, and its specificity ranges from $10 \%$ to $50 \%{ }^{4}$.

Due to the invasive behavior of E. histolytica and the noninvasive nature of $E$. dispar, coupled with the inability of microscopy to distinguish between the species, the World Health Organization (WHO) recommends that diagnoses attained by microscopy be recorded as "E. histolytica/E. dispar".

\footnotetext{
Address to: Dr. Eduardo Sergio da Silva. Campus Centro-Oeste Dona Lindu/ UFSJ. R. Sebastião Gonçalves Coelho 400, 35501-296 Divinópolis, MG, Brasil. Phone: 5537 3221-1584

e-mail: silvaedu@ufsj.edu.br

Received 21 October 2013

Accepted 29 January 2014
}

In 1997, the WHO also advocated procedures capable of ensuring differentiation between these species so that treatment is restricted to confirmed cases of E. histolytica infection. Biochemical, immunological, and molecular biology methods are now capable of differentiating between Entamoeba species ${ }^{5}$. Among these methods, tests for antigen detection in stool samples are advantageous in terms of speed, accuracy, and reliability 3,5

The objectives of our study were to compare the parasitological examination of stools with ELISA kit (IVD $\AA$ ) results as a screening test for the diagnosis of infections by Entamoeba sp., to diagnose E. histolytica using an enzyme immunoassay for the detection of a specific antigen, and to determine the prevalence of amebiasis in a sample of students from southeastern Brazil.

\section{METHODS}

This cross-sectional epidemiological study with a stratifiedsampling design included a total of 1,403 male and female students aged 6 to 14 years who attended 15 public schools in Divinópolis county, State of Minas Gerais, Brazil. The subjects lived in urban neighborhoods and rural communities, thus representing all of the county's 11 geographical areas. In the 
study period, Divinópolis had 10,656 students aged 6 to 14 years who were enrolled in 36 municipal schools. The city is approximately $100 \mathrm{~km}$ from Belo Horizonte, the state capital. Of its 213,016 residents, 207,516 live in urban neighborhoods, and 5,500 live in rural areas ${ }^{6}$.

Students whose parents or guardians agreed to fill in a questionnaire and to sign a consent form were given a collection cup with no preservatives. The samples (one per student) were transported on ice to the Universidade Federal de São João del-Rei (UFSJ) Laboratory of Immunology and Parasitology, prepared on the day of collection, and processed using the Hoffmann-Pons-Janer (HPJ, or Lutz) method ${ }^{7}$. To increase the likelihood of parasite detection, four qualified professional examined each sample ( $100 \%$ of fields read). An aliquot of each sample was stored at $-20^{\circ} \mathrm{C}$ for later coproantigen testing using an E. histolytica/E. dispar ELISA(Enzyme-linked immunosorbent assay) kit (IVD ${ }^{\circledR}$ Research, Carlsbad, CA, USA) for the in vitro detection (but not discrimination) of E. histolytica and E. dispar. According to the manufacturer's instructions, the immunoassay is based on the interaction of monoclonal antibodies conjugate with peroxidase that bind to antigens of $E$. dispar and $E$. histolytica, and the reaction is revealed by the addition of a substrate containing tetramethylbenzidine and peroxide. The kit has a sensitivity of $88 \%$ and a specificity of $100 \%{ }^{8}$. In comparison, the E. histolytica II kit (TechLab®, Blacksburg, VA, USA) is an immunoassay based on the interaction of monoclonal antibodies with the single antigenic determinant adhesin present at the galactose affinity E. histolytica. The kit has a sensitivity of $96.9 \%$ and a specificity of $100 \%{ }^{9}$. All tests were run and interpreted according to the manufacturer's instructions.

The data were encoded and processed using Statistical Package for the Social Sciences (SPSS) software, version 19.0, American University in Cairo - Department of University Academic Computing Technologies (UACT). The Chi-squared test was used to compare proportions, and the adopted significance level was $5 \%$ (p-value $<0.05$ ). To compare the microscopy test and the ELISA kit (IVD $\left.{ }^{\circledR}\right)$, the sensitivity and specificity, positive predictive value (PPV), and negative predictive value (NPV) were computed, assuming that the ELISA kit (IVD () can adequately serve as the gold standard, using a dichotomous approach ${ }^{10}$.

\section{Ethical considerations}

The investigation was approved by the research ethics committee (opinion 56/2009) and was performed from February 2010 to October 2011.

\section{RESULTS}

The microscopy results revealed a $5.7 \%(80 / 1,403)$ prevalence of infection for the E. histolytica/E. dispar complex. ELISA

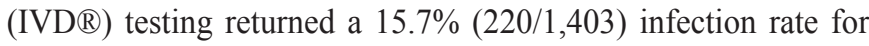
E. histolytica/E. dispar. A total of 45 (3.2\%) samples were positive by both tests, whereas $35(2.5 \%)$ were positive only by direct microscopy, and 175 (12.5\%) were positive only by ELISA(IVD®). Both tests were negative for 1148 (81.8\%) samples (Table 1).
In comparison with ELISA (IVD $®$ ), light microscopy showed $20 \%$ sensitivity and $97 \%$ specificity, with $56 \%$ PPV, $87 \%$ NPV, $44 \%$ false positives ( 1 - PPV), and 13\% false negatives.

The E. histolytica II kit (TechLab ${ }^{\circledR}$, Blacksburg, VA, USA), specific for E. histolytica, returned a 3.1\% (43/1403) infection rate for E. histolytica. The results of the ELISA (TechLab $\left.{ }^{\circledR}\right)$ and microscopy were positive in 18 (1.3\%) samples (Table 2).

Of the 1,403 samples, $52 \%(728 / 1403)$ were from females, and $48 \%(675 / 1403)$ were from males. The ages and genders of the subjects were evenly distributed. A significant association (p-value $=0.01$ ) was observed for E. histolytica with females but with not males.

E. histolytica infection was detected in all age groups, with the highest number of cases in individuals aged $>9$ and $\leq 12$ years (Figure 1). When the study population was segmented by age range, no significant association was observed for the age groups.

Divinópolis county is composed of 11 so-called planning regions, 2 of which are rural and 9 of which are urban. E. histolytica cases were detected in 7 regions (the Southeast, West, Northwest, Far Northwest, Rural Northwest, Far Southwest, and Rural Southeast).

TABLE 1 - Comparison of samples by light microscopy and ELISA (E. histolytica/E. dispar).

\section{ELISA}

E. histolytica/E. dispar

\begin{tabular}{|c|c|c|c|c|c|c|}
\hline \multirow[b]{2}{*}{ Microscopy } & \multicolumn{2}{|c|}{ Presence } & \multicolumn{2}{|c|}{ Absence } & \multicolumn{2}{|c|}{ Total } \\
\hline & $\mathrm{n}$ & $\%$ & $\mathrm{n}$ & $\%$ & $\mathrm{n}$ & $\%$ \\
\hline Positive & 45 & 3.2 & 35 & 2.5 & 80 & 5.7 \\
\hline Negative & 175 & 12.5 & 1,148 & 81.8 & 1,323 & 94.3 \\
\hline Total & 220 & 15.7 & 1,183 & 84.3 & 1,403 & 100.0 \\
\hline
\end{tabular}

ELISA: Enzyme-linked immunosorbent assay; E: entamoeba.

TABLE 2 - Light microscopy and ELISA (E. histolytica II ) results.

\section{ELISA}

\begin{tabular}{|c|c|c|c|c|c|c|}
\hline \multirow[b]{3}{*}{ Microscopy } & \multicolumn{4}{|c|}{ E. histolytica } & & \\
\hline & \multicolumn{2}{|c|}{ Presence } & \multicolumn{2}{|c|}{ Absence } & \multicolumn{2}{|c|}{ Total } \\
\hline & $\mathrm{n}$ & $\%$ & $\mathrm{n}$ & $\%$ & $\mathrm{n}$ & $\%$ \\
\hline Positive & 18 & 1.3 & 62 & 4.4 & 80 & 5.7 \\
\hline Negative & 25 & 1.8 & 1,298 & 92.5 & 1,323 & 94.3 \\
\hline Total & 43 & 3.1 & 1,360 & 96.9 & 1,403 & 100.0 \\
\hline
\end{tabular}

ELISA: Enzyme-linked immunosorbent assay; E: entamoeba. 


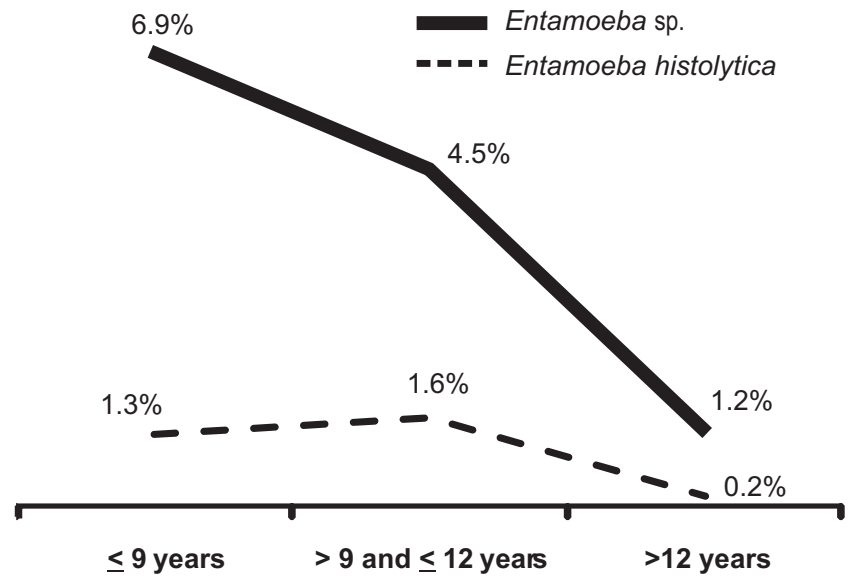

FIGURE 1 - Prevalence of E. histolytica and Entamoeba sp. in 6- to 14-yearold students, by age. Divinópolis, Minas Gerais, Brazil, from February 2010 to October $2011(\mathrm{n}=1,403)$.

\section{DIscussion}

Data on the prevalence of E. histolytica have emerged from studies on helminths and protozoans that were based on microscopic investigation of cysts and/or trophozoites in clinical specimens. Until relatively recently, E. histolytica and E. dispar were not differentiated, and infection with either of the two species was referred to as amebiasis, resulting in an overestimation of the true prevalence ${ }^{11}$.

However, the procedure for distinction has been reevaluated since Clark and Diamond ${ }^{12}$ demonstrated that E. histolytica and $E$. dispar are distinct species that, despite morphological similarities, differ in pathogenicity. The genus Entamoeba contains many morphologically similar species, several of which, including E. histolytica, E. dispar, E. moshkovskii, $E$. polecki, and $E$. hartmanni, can be found in human stools ${ }^{13,14}$.

Therefore, the epidemiology of amebiasis is confusing, mainly because of the recently appreciated distinctions between E. histolytica, E. dispar, and E. moshkovskii ${ }^{11}$. Because light microscopy does not efficiently identify $E$. histolytica, other tools have been developed to differentiate between Entamoeba species, including polymerase chain reaction (PCR), isoenzyme analysis, and ELISA, which are well suited for estimations of true prevalence and the treatment of patients ${ }^{5}$. Malatyali et al. ${ }^{15}$ advocated the use of sensitive and effective tests, such as ELISA, for antigen detection in stools.

Several epidemiological studies have been conducted to estimate the incidence and prevalence of amebiasis by testing commercially available antigens from various manufacturers ${ }^{11}$.

Our study distinguished E. histolytica from other amebae and strengthened existing epidemiological data. Moreover, the

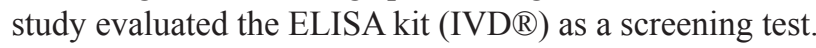

In the present investigation, microscopy underestimated the number of subjects infected with E. histolytica/E. dispar (5.7\%), in contrast to the E. histolytica/E. dispar ELISA kit (IVD®)

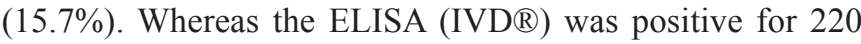
of the patients who had E. histolytica/E. dispar cysts in their stools, only 45 samples were positive in both tests. Additionally, 175 samples with negative results by direct microscopy were positive in the ELISA (IVD $®$ ) antigen detection test. This difference may be attributed to the quantity of the pathogen in the samples. Stools with a low number of cysts may be negative by direct microscopic examination but may yield positive results using ELISA ${ }^{3}$.

A comparison of the samples by light microscopy and ELISA (IVD®) revealed a low sensitivity $(20 \%)$ and a high specificity (97\%) for light microscopy. The high NPV of $87 \%$ reduced the likelihood of false-negative results, yet the low PPV of 56\% rendered the test unreliable. However, positivity on microscopy does not rule out the possibility that $44 \%$ of the samples are negative. Delialioglu et al. ${ }^{3}$ reported that microscopy provided $53.8 \%$ sensitivity and $94 \%$ specificity, with $78 \%$ PPV and $17 \%$ NPV, relative to an ELISA kit (Ridascreen Entamoeba, R-Biopharm AG, Darmstadt, Germany). In another study, compared with an ELISA triage kit (ProSpecT EIA, Alexon Inc., Sunnyvale, CA, USA), microscopy was more specific (92.1\%) but less sensitive $(68.4 \%)^{16}$. The ELISA kit (Alexon-Trend, Inc., Sunnyvale, CA, USA) had a sensitivity of $54.5 \%$ and a specificity of $94 \%$. If matched with culture and microscopy, the sensitivity of direct microscopic examination was $66 \%$, and the specificity was $83.7 \%$. However, the results should be confirmed with a larger number of fecal samples ${ }^{17}$.

Considering these data, the low sensitivity of microscopy may have been influenced by the collection of a single stool sample per student. According to $\operatorname{Ravdin}^{18}$, the examination of three separate stool specimens is required to attain $90 \%$ sensitivity, and a single examination identifies only $40 \%$ to $60 \%$ of infections. If feces were collected more than once and were fixed in preservatives, a higher prevalence of $E$. histolytica/E. dispar would be expected ${ }^{11}$. These data suggest that the ELISA (IVD®) can be used as a screen for the immediate testing of stools. The performance of antigen detection assays suggests that they may be considered as reference standards for the detection of E. histolytica and E. dispar ${ }^{5,19}$.

However, microscopy should still be considered as a screening method for the detection of Entamoeba found in human stools, despite the fact that this technique cannot differentiate between E. histolytica, E. moshkovskii, and E. dispar, although E. polecki, E. coli, and E. hartmanni can be differentiated morphologically from $E$. histolytica ${ }^{20}$.

One of the problems with screening kits is that they cannot differentiate between the amebae. However, the ELISA kit $\left(\right.$ TechLab $\left.{ }^{\circledR}\right)$ is commercially available for the specific, direct detection of an $E$. histolytica antigen in stool specimens ${ }^{5,19}$. In the 1,403 samples subjected to ELISA (TechLab ${ }^{\circledR}$ ), the prevalence of $E$. histolytica was $3.1 \%$. Haque et al. ${ }^{21}$, based on isoenzyme analysis of 202 samples from symptomatic individuals seen at the International Center for Diarrheal Disease Research in Dhaka, Bangladesh, obtained 52 culture-positive results using the E. histolytica II ELISA kit (TechLab $\left.{ }^{\circledR}\right)$, a method that 
ensured faster diagnosis than when using isoenzyme analysis and achieved a higher sensitivity and specificity than did microscopy. The E. histolytica II ELISA (TechLab ${ }^{\circledR}$ ) correctly identified 21 of 22 cases of E. histolytica infection and 28 of 30 for $E$. dispar cases. Haque et al. ${ }^{19}$, examining 2000 samples using two TechLab ${ }^{\circledR}$ kits (the E. histolytica II ELISA kit and an Entamoeba ELISA kit), reported prevalence rates of $4.2 \%$ for $E$. histolytica and $6.5 \%$ for $E$. dispar in children aged 1 to 14 years who were living in the vicinity of Dhaka and presenting with diarrhea. In contrast, in asymptomatic children, the percentages were $1 \%$ for $E$. histolytica and $7 \%$ for $E$. dispar. Following the same strategy, Nesbitt et al. ${ }^{22}$ examined 842 samples from Kilimanjaro, Tanzania, and detected prevalence values of $1 \%$ for $E$. histolytica and $7.3 \%$ for $E$. dispar. The high prevalence of $E$. histolytica infection detected in the present study warrants the implementation of actions directed toward health promotion and preventive measures.

The present results also corroborate previous finding $\mathrm{s}^{23}$ that indicated that females are more prone than males to E. histolytica infection. In Brazil, amebiasis rates are highest in the northern region of the country, where both intestinal and extraintestinal forms of the disease exist, with serious public health implications ${ }^{24}$. In Belém, the capital city of the northern state of Pará, a prevalence rate of $29.35 \%$ has been reported using the E. histolytica II ELISA (TechLab $\left.{ }^{\circledR}\right)^{25}$. The highest reported E. histolytica prevalence rates in Brazil that were detected using the E. histolytica II kit (TechLab $\left.{ }^{\circledR}\right)$ were $36.6 \%(30 / 82)$ for stool samples from the state of Rondônia in Ariquemes and 19.4\% (26/134) for stools taken from residents of Monte Negro ${ }^{26}$.

In Pernambuco state, in northeastern Brazil, Dourado et al. ${ }^{27}$ detected only E. dispar, whereas in Macaparana county, within the same state, all samples investigated by Pinheiro et al..$^{28}$ tested negative in an E. histolytica-specific ELISA (TechLab $\left.{ }^{\circledR}\right)$ and positive for $E$. dispar using a molecular biology method.

In southeastern Brazil, using light microscopy, Santos et al. ${ }^{29}$ detected a $21 \%$ prevalence of the $E$. histolytica/E. dispar complex in urban and rural areas of Rio de Janeiro State, yet only two samples tested positive for E. histolytica by PCR and E. histolytica II ELISA (TechLab®). However, in São Leopoldo, within the southern State of Rio Grande do Sul, Tomé and Tavare $^{30}$ found no cases of $E$. histolytica infection using the E. histolytica II ELISA (TechLab®).

Light microscopy has several limitations when applied to the diagnosis of amebiasis, given factors such as examiner experience and similarities between Entamoeba cysts $^{3}$, which can increase the likelihood of false-positive results ${ }^{4}$. Despite the low cost of light microscopy compared with culture, isoenzyme analysis, antigen detection, and PCR, the method's dependence on subjective diagnosis limits its reliability ${ }^{3}$. Therefore, microscopy is not appropriate for either rapid disease diagnosis or prevalence studies.

According Ngui et al. ${ }^{31}$, molecular techniques are indeed promising tools for epidemiological studies, particularly in discriminating the pathogenic from the non-pathogenic species of Entamoeba. E. moshkovskii, another morphologically indistinguishable human parasitic Entamoeba, has not been mentioned, nor has it been considered a contributor to prevalence figures in endemic areas ${ }^{11}$. Molecular techniques that can differentiate all studied species of Entamoeba, including E. moshkovskii, in human specimens have already been reported in Italy, Bangladesh, India, Australia, Turkey, Iran, and Malaysia ${ }^{31-36}$.

It is necessary to use new techniques to differentiate Entamoeba diagnoses ${ }^{37}$ and to establish a readily available and cost-effective test for the specific diagnosis of amebiasis caused by $E$. histolytica in public laboratories ${ }^{26}$.

Diagnostic methods that are more sensitive and specific than light microscopy are required to establish the true distributions of E. histolytica and to reduce the rates of unnecessary treatment, thereby discouraging the development of drug resistance, precluding the risks of side effects, and reducing the costs of hospitalization. The present findings demonstrate that the ELISA kit (IVD $\left.{ }^{\circledR}\right)$ can be used as an alternative screening tool. In addition, this assay could be utilized by personnel who do not have extensive training in manual parasitological methods. The determination of the true prevalence of E. histolytica infection among students from southeastern Brazil is very crucial, as this information will lead to a better understanding of the public health problem and will help outline measures for controlling amebiasis.

\section{ACKNOWLEDGMENTS}

The authors wish to thank the Program for Health Education through Work of the Brazilian Ministry of Health, the University Extension Program (ProExt) of the Higher Education Division of the Brazilian Ministry of Education, and the Universidade Federal de São João del- Rei in Minas Gerais.

\section{CONFLICT OF INTEREST}

The authors declare that there is no conflict of interest.

\section{REFERENCES}

1. World Health Organization (WHO). Amoebiasis. Weekly Epidemiological Record 1997; 72:97-100.

2. Huston CD, Petri WA. Amebiasis: clinical Implications of the recognition of Entamoeba dispar. Curr Infect Dis 1999; 1:441-447.

3. Delialioglu N, Aslan G, Sozen M, Babur C, Kanik A, Emekdas G. Detection of Entamoeba histolytica/Entamoeba dispar in Stool Specimens by Using Enzymelinked Immunosorbent Assay. Mem Inst Oswaldo Cruz 2004; 99:769-772.

4. Petri WA, Haque R, Lyerly D, Vines RR. Estimating the impact of amebiasis on health. Parasitol Today 2000; 16:320-321.

5. Haque R, Petri WA. Diagnosis of amebiasis in Bangladesh. Arch Med Res 2006; 37:273-276.

6. Instituto Brasileiro de Geografia e Estatística (IBGE). Cidades [Internet]. [Cited 2011 July 10] Available at: http://www.ibge.gov.br/cidadesat/topwindow.htm?1.

7. Hoffmann WA, Pons JA, Janer JL. The sedimentation concentration method in Schistosomiasis mansoni. Puert Rico J Publ Health 1934; 2:283-298. 
8. ELISA kits Entamoeba histolytica/Entamoeba dispar -IVD $\mathbb{R}^{\circledR}$ Research, Carlsbad, CA, USA - kit label; 2011.

9. ELISA kits E. histolytica II - Techlab ${ }^{\circledR}$, Blacksburg, VA, USA - kit label; 2011.

10. Fletcher RH, Fletcher SW. Epidemiologia Clínica Elementos Essenciais, Porto Alegre: Artmed; 2006.

11. Tengku SA, Norhayati M. Public health and clinical importance of amoebiasis in Malaysia: A review.Trop Biomed 2011; 28:194-222.

12. Clark CG, Diamond LS. A redescription of Entamoeba histolytica Schaudinn, 1903 (Emended Walker, 1911) separating it from Entamoeba dispar Brumpt, 1925. J Eukaryot Microbiol 1993; 40:340-344.

13. Clark CG, Diamond LS. Ribosomal RNA genes of 'pathogenic' and 'nonpathogenic' Entamoeba histolytica are distinct. Mol Biochem Parasitol 1991; 49:297-302.

14. Silva EF, Gomes MA. Parasitologia Humana - Amebíase: Entamoeba histolytica/Entamoeba díspar. 12 $2^{\text {rd }}$ ed. São Paulo: Atheneu; 2011.

15. Malatyalı E, Ozçelik S, Celiksöz A. The investigation of Entamoeba histolytica prevalence in some villages of Sivas by ELISA method. Türkiye Parazitol Derg 2011; 35:6-9.

16. Pillai DR, Keystone JS, Sheppard DC, MacLean JD, MacPherson DW, Kain KC. Entamoeba histolytica \& Entamoeba dispar: epidemiology and comparison of diagnostic methods in a setting of non endemicity. Clin Infect Dis 1999; 29:1315-1318.

17. Gatti S, Swierczynski G, Robinson F, Anselmi M, Corrales J, Moreira J, et al. Amebic infections due to the Entamoeba histolytica-Entamoeba dispar complex: a study of the incidence in a remote rural area of Ecuador. Am J Trop Med Hyg 2002; 67:123-127.

18. Ravdin JI. Diagnosis of invasive amoebiasis - time to end the morphology era. Gut 1994; 35:1018-1021

19. Haque R, Faruque ASG, Hahn P, Lyerly DM, Petri WA. Entamoeba histolytica and Entamoeba dispar infection in children in Bangladesh. J Infect Dis 1997; 175:734-736.

20. Santos HLC, Bandyopadhyay K, Bandea R, Peralta RHS, Peralta JM, Silva AJ. LUMINEXW: a new technology for the simultaneous identification of five Entamoeba spp. commonly found in human stools. Parasites \& Vectors 2013; 6:1-9.

21. Haque R, Neville LM, Hahn P, Petri WA. Rapid diagnosis of Entamoeba infection by using Entamoeba and E. histolytica stool antigen detection kits. J Clin Microbiol 1995; 33:2558-2561.

22. Nesbitt RA, Mosha FW, Katki HA, Ashraf M, Assenga C, Lee CM, et al. Amebiasis and comparison of microscopy to Elisa technique in detection of Entamoeba histolytica and Entamoeba dispar. J Nat Med Assoc 2004; 96:671-677.

23. Blessmann J, Van LP, Nu PAT, Thi HD, Muller-Myhsok B, Buss H, et al. Epidemiology of amebiasis in a region of high incidence of amebic liver abscess in central Vietnam. Am J Trop Med Hyg 2002; 66:578-583.

24. Cunha AS, Silva EF, Raso P, Melo SM. Patogenia da amebíase I. Aspectos clínicos da amebíase no Brasil com especial referência aos estudos realizados em 3 grupos populacionais de regiões geográficas distintas. Rev Inst Med Trop São Paulo 1977; 19:289-300.

25. Silva MCM, Monteiro CSP, Araújo BAV, Silva JV, Póvoa MM. Determinação da infecção por Entamoeba histolytica em residentes da área metropolitana de Belém, Pará, Brasil, utilizando ensaio imunoenzimático (ELISA) para detecção de antígenos. Cad Saúde Pública 2005; $21: 969-$ 973.

26. Santos RV, Nunes JS, Camargo JASA, Rocha EMM, Fontes G, Camargo LMA. High occurrence of Entamoeba histolytica in the municipalities of Ariquemes and Monte Negro, State of Rondônia, Western AmazoniaBrazil. Rev Inst Med Trop Sao Paulo 2013;55:193-196.

27. Dourado A, Maciel A, Aça IS. Occurrence of Entamoeba histolytica/ Entamoeba dispar in ambulatory patients of Recife, PE. Rev Soc Bras Med Tropl 2006; 39:388-389.

28. Pinheiro SMB, Carneiro RM, ACA IS, Irmão JI, Morais JRMA, Coimbra MRM, et al. Determination of the prevalence of Entamoeba histolytica and E. dispar in the Pernambuco state of Northeastern Brazil by a polymerase chain reaction. Am J Trop Med Hyg 2004; 70:221-224.

29. Santos HL, Peralta RH, Macedo HW, Barreto MG, Peralta JM. Comparison of multiplex-PCR and antigen detection for differential diagnosis of Entamoeba histolytica. Braz J Infect Dis 2007; 11:365-370.

30. Tomé JBS, Tavares RG. Differentiation between Entamoeba histolytica and Entamoeba dispar by means of immunoenzymatic assay for antigen detection in children fecal samples. Rev Inst Adolfo Lutz 2007; 66:305-307.

31. Ngui R, Angal L, Fakhrurrazi SA, Ai Lian YL, Ling LY, Ibrahim J, et al. Differentiating Entamoeba histolytica, Entamoeba dispar and Entamoeba moshkovskii using nested polymerase chain reaction (PCR) in rural communities in Malaysia. Parasit Vectors 2012; 5:187-193.

32. Ali IK, Hossain MB, Roy S, Ayeh-Kumi PF, Petri Jr WA, Haque R, et al. Entamoeba moshkovskii infections in children, Bangladesh. Emerg Infect Dis 2003; 9:580-584.

33. Fotedar R, Stark D, Beebe N, Marriott D, Ellis J, Harkness J. Laboratory diagnostic techniques for Entamoeba species. Clin Microbiol Rev 2007; 20:511-532.

34. Fotedar R, Stark D, Marriott D, Ellis J, Harkness J. Entamoeba moshkovskii infections in Sydney, Australia. Eur J Clin Microbiol Infect Dis 2008; 27:133-137.

35. Solaymani-Mohammadi S, Rezaian M, Babaei Z, Rajabpour A, Meamar AR, Pourbabai AA, et al. Comparison of a stool antigen detection kit and PCR for diagnosis of Entamoeba histolytica and Entamoeba dispar infections in asymptomatic cyst passers in Iran. J Clin Microbiol 2006; 44: 2258-2261.

36. Tanyuksel M, Ulukanligil M, Guclu Z, Araz E, Koru O, Petri WA Jr. Two cases of rarely recognized infection with Entamoeba moshkovskii. Am J Trop Med Hyg 2007; 76:723-724.

37. Duarte IAC, Santos RV, Fontes G, Galindo LF, Ximenes RAA, Maciel MAV, et al. Prevalencia de infección por Entamoeba histolytica en escuelas públicas de la ciudad de Maceió, Alagoas, Brasil. Rev Cubana Med Trop $2013 ; 65: 7-12$. 